\title{
Biodiversity of rodent fleas in plague endemic areas of India
}

\author{
M. Shelly ${ }^{1,2^{*}}$, S. Biswas ${ }^{1}$, M. S. Reddy ${ }^{2}$ and Sohan $L$ al ${ }^{1}$ \\ ${ }^{1}$ NCDC, NTI Campus, 8 Bellary Road, Bangalore-560003, INDIA \\ ${ }^{2}$ Department of Zoology, Bangalore University, Bangalore-560056, INDIA \\ *Corresponding author.E-mail: shelly1mandal@gmail.com \\ Received: April 24, 2013; Revised received: J une 24, 2013; Accepted: J uly 10, 2013
}

Abstract: Rodent fleas have been considered as the main vector for plague transmission in the rodent population and human plague outbreak usually occur due to the close association of infected rodent fleas with the human being. A total of 910 fleas were retrieved from the 2128 rodents collected from the different areas like Kolar, Palamner, Pune, Surat, Rohru and Chennai. Mainly two types of rodent fleas i.e. Xenopsyalla astia and X. cheopis were found in these areas except the Dodra Kawar area of H.P. state. In Dodra Kawar area Neopsylla kawar species were found and it was very sensitive to the temperature variation. Dodra kawar area usually remains under snow for about nine months and even in the rest of period the maximum temperature does not go more than $20^{\circ} \mathrm{C}$. The distribution of X. astia and X. cheopis were found uneven. In surat of Gujarat state X. cheopis was predominantly high, whereas in rest of the area $X$. astia were found more. In Chennai the main species found was $X$. astia only. The female percent of rodent flea may be considered as a good indicator for the fast propagation of rodent flea. The breading season for the fleas mostly depends on the climatic condition like temperature below $22^{\circ} \mathrm{C}-25^{\circ} \mathrm{C}$, humidity more than $70 \%$ even if the outside temperature is more still the shady area the favorable and do help in the survival of fleas. The rapid urbanization and mass use of pesticide in agriculture sector has got significant impact on the rodent flea population and development of resistance to pesticides.

Keywords: Biodiversity, Flea index, Plague, Rodent fleas, Xenopsylla spp.

\section{INTRODUCTION}

Plague is a zoonotic disease, its pneumonic form spread very fast in human beings. Natural cycle of plague occurs and remains in rodent population and continues mostly through the infected rodent flea bite. Rodent fleas are the main vectors responsible for its transmission from rodent to rodent and rodent to human being (Rathnaswamy, 1974). It is highly fatal in human being if not treated early. The third pandemic of plague started in 1890 's and caused a heavy death toll throughout the world (Samuel and Cohn, 2008). A century ago, there were more than 25 million of deaths In India, (including Bangladesh and Pakistan) alone in two decades period (1898-1918). The development of antibiotics such as Streptomycin and Sulphonamide after the Second World War, led to dramatic reduction in the plague cases. Moreover it was also attributed to the universal use of DDT spray in rural areas for mosquito control, because the rodent fleas were also sensitive to DDT at that time (Biswas et al., 2011). The mortality rate of plague came down from 183 to 1.8 per population and finally reached to zero level during 1967. In 1966 Mulbagal area of Kolar district reported a last case of plague. Sporadic cases of plague were also reported after 1967 from Himachal Pradesh, Attebele Karnataka in 1983 and 1984. The sylvatic plague incidences were detected and reported by plague surveillance unit of National Institute of Communicable Disease in the tri-junction area of Karnataka, Andhra Pradesh and Tamil Nadu. After a quiescence period of 28 years, plague re-emerged in 1994. Both types of plague (Bubonic and Pneumonic) cases were reported from Beed district of Maharashtra and Surat of Gujarat. The probable reason for this was the discontinuation of plague surveillance and control unit in these states. A lesson was learnt from this outbreak and plague surveillance and control units were re-started in both these states. Again after 8 years of long quiescence localized pneumonic plague outbreaks were reported from Hatkoti, Shimla (Himachal Pradesh) in 2002 and 2004 in Dangud village, district Uttarkashi (Uttarakhand). The seriousness of plague was well documented by W.H.O. Twenty six countries had reported 53,417 cases $4060(7.6 \%)$ deaths to W.H.O. Though it is well known fact that the under reporting is always there due to various factors which are beyond the control of administration (Bulter, 1989 and Biswas et al., 2011).

Baltzard and Bahmanyar (1958) studied and concluded that plague is not localized but time to time it shifts from one place to other due to the rodent migration and the vector too. The rodent fleas as main vector are responsible for its continuity. Various biotic and abiotic 
factors are also responsible for the outbreaks of plague. The containment of plague was well done with the vector control by the use of DDT. But now the scenario has changed. In the beginning the rodent fleas were very sensitive to DDT and now it has developed resistance (Biswas et al., 2008). This is posing a threat and generates a need to find the other ways or means to contain the development of rodent fleas. The high population growth, rapid transport system and fast development of various pesticides/insecticides and antibiotic and their uncontrolled uses in agriculture sector and in health sector will have some impact in almost all sphere of life and it might have affected the nature of the plague vector. Therefore the present study has been made to find out, the biodiversity of the plague vector in India particularly in the plague endemic areas.

\section{MATERIALS AND METHODS}

The study area was in Kolar district of Karnataka, which is bordering to both Tamil Nadu and Andhra Pradesh which lies between $77^{\circ} 21^{\prime}$ to $78^{\circ} 35^{\prime}$ east longitude and $20^{\circ} 46^{\prime}$ to $130^{\circ} 58^{\prime}$ north latitude. This area is most significant because the last human case was detected from the Mulbagal area of this district in 1966. The seropositivity for plague in rodents was also detected in this district in the past. Other plague endemic areas from where the study samples were collected, were Chittoor district (AP), Chennai (TN), Surat (Gujarat), Pune (Maharashtra) and Rohru (HP).

Rodents were collected by digging from the wild situation and by using wonder traps (live multiple catch trap) from the domestic and peri-domestic situations. The fleas were retrieved from the live rodents collected, by combing and then sucking with the help of flea suction apparatus. The fleas so collected were transferred into a larger test tube and plugged with cotton. These were then transported to laboratory in a proper container whose temperature is maintained to $20^{\circ} \mathrm{C}-25^{\circ} \mathrm{C}$ and then preserved in small tubes containing 70\%-80\% alcohol and for further processing. The fleas were processed for proper identification as per the standard method described by Iyengar, (1973).

\section{RESULTS}

The rodent fleas collected from the various places of different states were processed and identified. The data generated is presented in the tables mentioned Tables 1 to 4 and Figs. 1 to 3.

\section{DISCUSSION}

Plague is one of the most complicated vectors born zoonotic disease. Rodent act as reservoir and efficient vector i.e. rodent flea results in the active transmission of the causative agent plague bacilli (Yersinia pestis). There are 2500 species of fleas in the world belonging to order Siphonaptera, and out of it 46 species described by Sharma (2012) were found to be in India alone. Among these 46 species, Xenopsylla spp. like X. astia and X. cheopis were found predominantly in many areas. The other species were not found on the rodents collected from most of the plague endemic areas. The findings on rodent collected and the type of species of the ectoparasites are presented in the table. It indicate that the vector density of female fleas has gone $>50 \%$ in the months of June to December in Kolar district (KA). The climatic condition during these months like mean

Table 1. Data of plague vector in Kolar (KA) area for the period of 2009-2010.

\begin{tabular}{|c|c|c|c|c|c|c|c|c|c|c|c|}
\hline $\begin{array}{l}\dot{Z} \\
\bar{n}\end{array}$ & 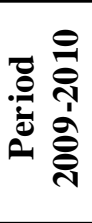 & $\stackrel{x}{x^{x}}$ & $\stackrel{\dot{\Sigma}}{\Sigma}$ & 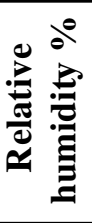 & $\begin{array}{l}\xi \\
\varepsilon \\
\frac{1}{0}\end{array}$ & 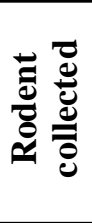 & $\frac{\mathscr{B}}{\square} \frac{\bar{d}}{\bar{y}}$ & 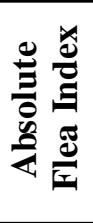 & 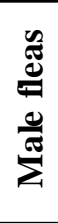 & 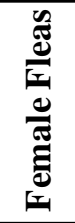 & 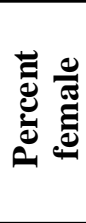 \\
\hline 1 & Jan & 33 & 10 & 60 & 2 & 105 & 64 & 0.61 & 30 & 34 & 53 \\
\hline 2 & Feb & 37 & 11 & 52 & 4 & 87 & 30 & 0.34 & 22 & 8 & 27 \\
\hline 3 & Mar & 38 & 10 & 46 & 20 & 0 & 0 & 0 & 0 & 0 & 0 \\
\hline 4 & Apr & 38 & 18 & 54 & 82 & 51 & 15 & 0.29 & 6 & 9 & 60 \\
\hline 5 & May & 38 & 15 & 64 & 122 & 66 & 14 & 0.21 & 8 & 6 & 43 \\
\hline 6 & Jun & 38 & 14 & 74 & 112 & 50 & 12 & 0.24 & 3 & 9 & 75 \\
\hline 7 & Jul & 37 & 11 & 77 & 139 & 50 & 5 & 0.10 & 2 & 3 & 60 \\
\hline 8 & Aug & 38 & 9 & 79 & 148 & 23 & 8 & 0.35 & 5 & 3 & 37 \\
\hline 9 & Sep & 33 & 11 & 76 & 188 & 31 & 6 & 0.19 & 1 & 5 & 83 \\
\hline 10 & Oct & 39 & 12 & 78 & 202 & 65 & 14 & 0.21 & 1 & 13 & 93 \\
\hline 11 & Nov & 33 & 12 & 73 & 62 & 82 & 21 & 0.26 & 9 & 12 & 57 \\
\hline 12 & Dec & 32 & 12 & 68 & 17 & 100 & 26 & 0.26 & 11 & 15 & 58 \\
\hline \multicolumn{6}{|c|}{ Total } & 710 & 215 & 0.30 & 98 & 117 & 54 \\
\hline
\end{tabular}


Table 2. Data of plague vector in Palamner (AP) area for the period of 2009-2010.

\begin{tabular}{|c|c|c|c|c|c|c|c|c|c|c|c|}
\hline \multirow{2}{*}{$\begin{array}{l}\dot{2} \\
\dot{\bar{n}}\end{array}$} & \multirow{2}{*}{ 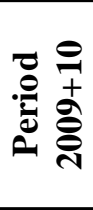 } & \multicolumn{2}{|c|}{ Temp. ${ }^{\circ} \mathrm{C}$} & \multirow{2}{*}{ 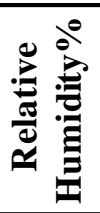 } & \multirow{2}{*}{ 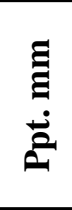 } & \multirow{2}{*}{ 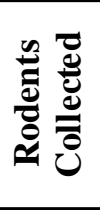 } & \multirow{2}{*}{$\frac{\mathscr{\Phi}}{4} \frac{\bar{d}}{\bar{y}}$} & \multirow{2}{*}{$\begin{array}{l}\frac{8}{0} \\
\frac{8}{5} \\
\frac{8}{0} \\
\frac{8}{8} \\
\frac{8}{4}\end{array}$} & \multirow{2}{*}{$\frac{\frac{0}{\sigma}}{\sum} \frac{\mathbb{D}}{4}$} & \multirow{2}{*}{ 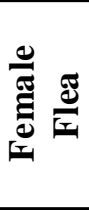 } & \multirow{2}{*}{ 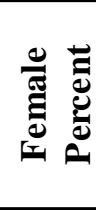 } \\
\hline & & $\stackrel{x}{x}^{\dot{0}}$ & $\dot{\Sigma}$ & & & & & & & & \\
\hline 1 & Jan & 35 & 12 & 74 & 21 & 95 & 39 & 0.41 & 23 & 16 & 41 \\
\hline 2 & Feb & 40 & 13 & 72 & 15 & 110 & 77 & 0.7 & 37 & 40 & 51 \\
\hline 3 & Mar & 39 & 18 & 71 & 23 & 148 & 85 & 0.57 & 31 & 54 & 63 \\
\hline 4 & Apr & 43 & 18 & 72 & 24 & 115 & 45 & 0.39 & 25 & 20 & 44 \\
\hline 5 & May & 45 & 20 & 65 & 53 & 100 & 30 & 0.3 & 14 & 16 & 53 \\
\hline 6 & Jun & 43 & 19 & 63 & 87 & 110 & 40 & 0.36 & 13 & 27 & 67 \\
\hline 7 & Jul & 40 & 20 & 65 & 109 & 87 & 34 & 0.39 & 16 & 18 & 53 \\
\hline 8 & Aug & 40 & 21 & 69 & 137 & 125 & 48 & 0.38 & 20 & 28 & 58 \\
\hline 9 & Sep & 39 & 20 & 72 & 134 & 81 & 28 & 0.34 & 9 & 19 & 68 \\
\hline 10 & Oct & 37 & 18 & 80 & 336 & 70 & 31 & 0.44 & 10 & 21 & 68 \\
\hline 11 & Nov & 39 & 18 & 81 & 374 & 127 & 43 & 0.34 & 8 & 35 & 81 \\
\hline 12 & Dec & 39 & 17 & 77 & 152 & 82 & 29 & 0.35 & 10 & 19 & 66 \\
\hline \multicolumn{6}{|c|}{ Total } & 1250 & 529 & 0.42 & 216 & 313 & 56 \\
\hline
\end{tabular}

Table 3. Bio diversity of rodent fleas in plague endemic areas.

\begin{tabular}{|c|c|c|c|c|c|c|c|}
\hline Place & 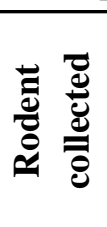 & $\frac{\mathscr{g}}{\overline{\mathscr{B}}} \frac{\bar{d}}{\overline{\bar{\theta}}}$ & 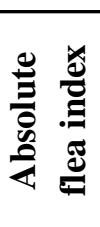 & $\frac{\frac{\theta}{\sigma}}{\Sigma}$ & 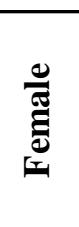 & 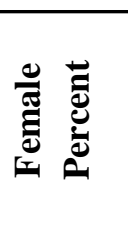 & 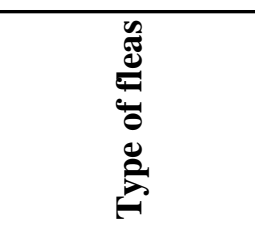 \\
\hline Kolar (KA) & 710 & 215 & 0.30 & 98 & 117 & 54 & $X a, X_{c}$ \\
\hline Palamner (AP) & 1250 & 529 & 0.42 & 216 & 313 & 59 & $X_{a}, X_{c}$ \\
\hline Surat (Gujarat) & 41 & 10 & 0.24 & 1 & 9 & 90 & $X_{c}, X_{a}$ \\
\hline Pune (Maharastra) & 25 & 45 & 1.76 & 10 & 35 & 77.7 & $X_{a}, X_{c}$ \\
\hline Rohru (HP) & 44 & 24 & 0.54 & 4 & 20 & 83 & Neopsylla kawar \\
\hline Chennai (TN) & 58 & 87 & 1.5 & 56 & 31 & 35.6 & $\mathrm{Xa}$ \\
\hline Total & 2128 & 910 & 42.76 & 385 & 525 & 57.6 & $\mathrm{Xa}, \mathrm{Xc}, \mathrm{Nk}$ \\
\hline
\end{tabular}

Xa - Xenopsylla astia, Xc - Xenopsylla cheopis, Nk - N eopsylla kawar

KA - Karnataka; AP - Andhra Pradesh; HP - Himachal Pradesh; TN - Tamil Nadu

temperature $\left(22^{\circ} \mathrm{C}-25^{\circ} \mathrm{C}\right)$, humidity $>70 \%$ and two monsoon rains also favored for their multiplication. Thus the breeding season in this area may be mainly January and June to December months. Whereas in the adjoining state AP, the female flea percent showed that the breeding of fleas may be less in the months of January, February, April, May and July. The female percent of rodent flea may be considered as a good indicator for the fast propagation of rodent flea. The precipitation and humidity as well as the temperature do have major role in the survival and multiplication of rodent fleas. The absolute flea index i.e. the indicator of flea concentration was found more (0.40) in A.P. state than (0.32) Karnataka.

Seal, 1960 and 1969 made epidemiological studies on plague and described the distribution of plague vector in Bombay, Madras and Calcutta. It was reported that the rodent flea species were mainly $X$. astia, $X$. cheopis and very few as $X$. brasiliensis. The $X$. astia sepcies was $65.6 \%$ in Calcutta, $94.3 \%$ in Madras region, where as $X$. cheopis was $76.3 \%$ in Bombay. The present study revealed that there was not much change in the type of species occurring in the plague endemic areas when compared to the observations made about 60 year back.

There is a significant decrease in the absolute flea index ranging (0.32-0.40) in Kolar and Palamner areas when compared to the position (1.23-2.63) described by Krishnamurthy et al. (1965). It was in the range of 6.3 in 1930 in Bombay. This also came down in the year 1953 to a level of 1.58 (Seal, 1960 and 1969). This downward trend may be attributed to the modernization; rapid urbanization and use of pesticides in the agriculture sector. A rapid survey done by Kumar et al. (1996) in and around Delhi 


\section{Bio Diversity of Rodent Flea}

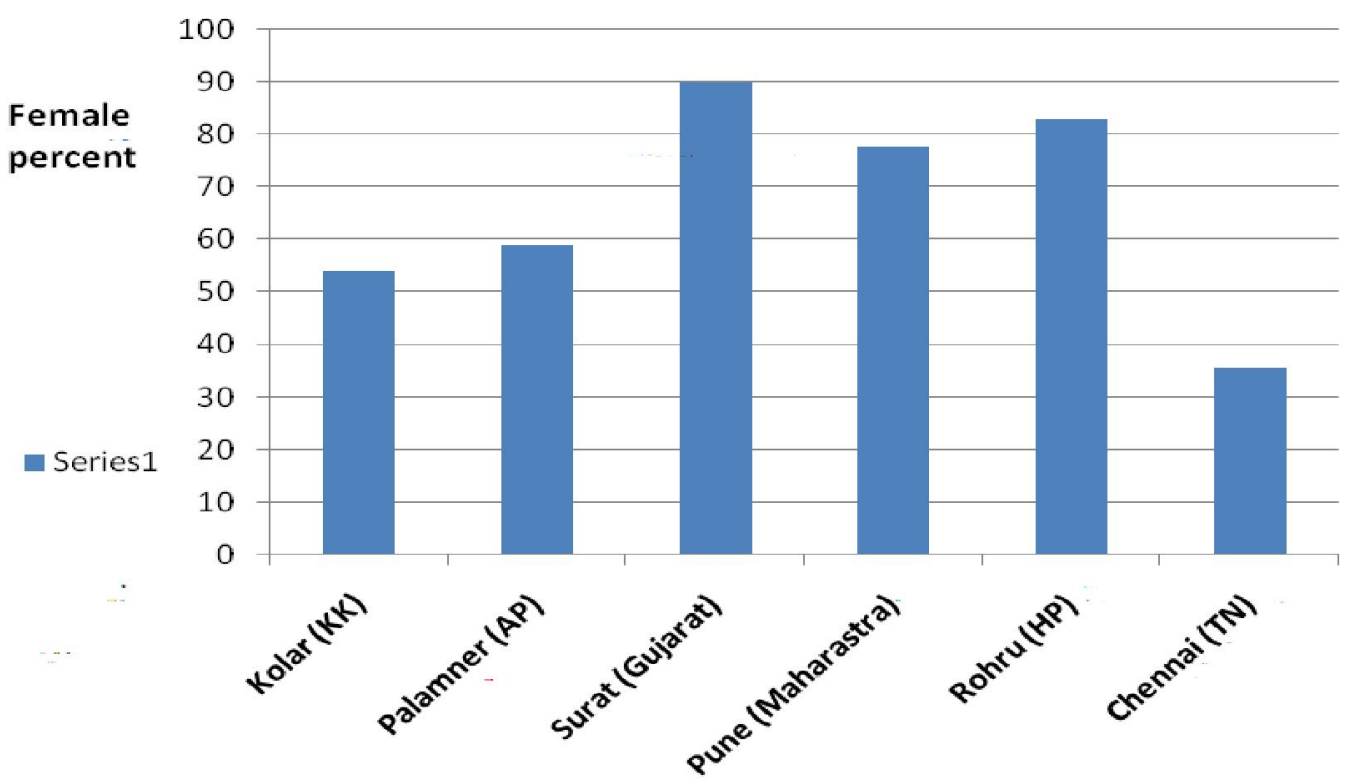

Fig. 1. Bio-diver sity of rodent flea.

in September 1994 at the time of plague outbreak in Surat does indicate the range of absolute flea index from 0.08 to 4.0. It was further stressed that it varies from place to place and the number of factors were responsible for this.

The comparative assessment of rodent fleas absolute index in different states do indicate that the load of rodent fleas was more in, Rohru (HP) and Pune (Maharashtra) and Chennai (TN) areas than that of Surat (Gujarat), Kolar (KA), Palamner (AP). However the importance lies with the specific vector species critical index $(>1)$ in that region and the various factors which favours the transmission of the causative agent from the reservoir to the human being. The rodent flea species like Neopsylla kawar which was found in Dodra Kawar area of HP state may or may not be the efficient vector because the evidence of plague organism in this flea was not available. In Dodra Kawar area Neopsylla kawar species was very sensitive to the temperature variation. Dodra kawar area usually remains under snow for about nine months and

\section{Absolute Flea Index}

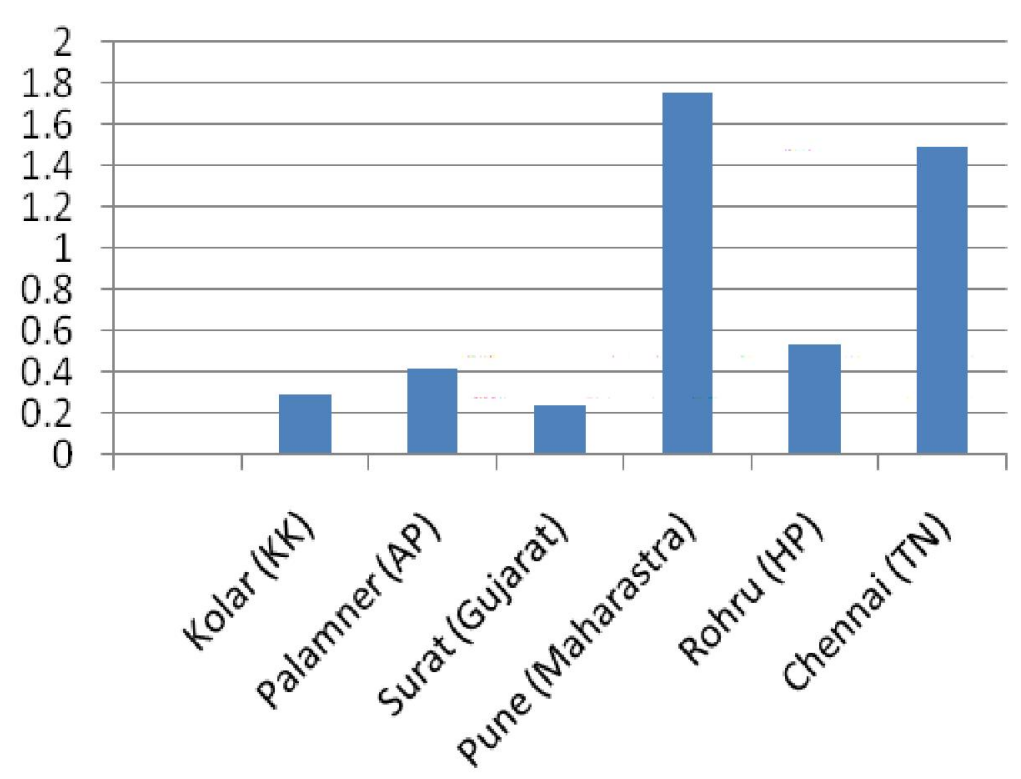

- Absolute Flea Index

Fig. 2. Absolute flea index of various places. 


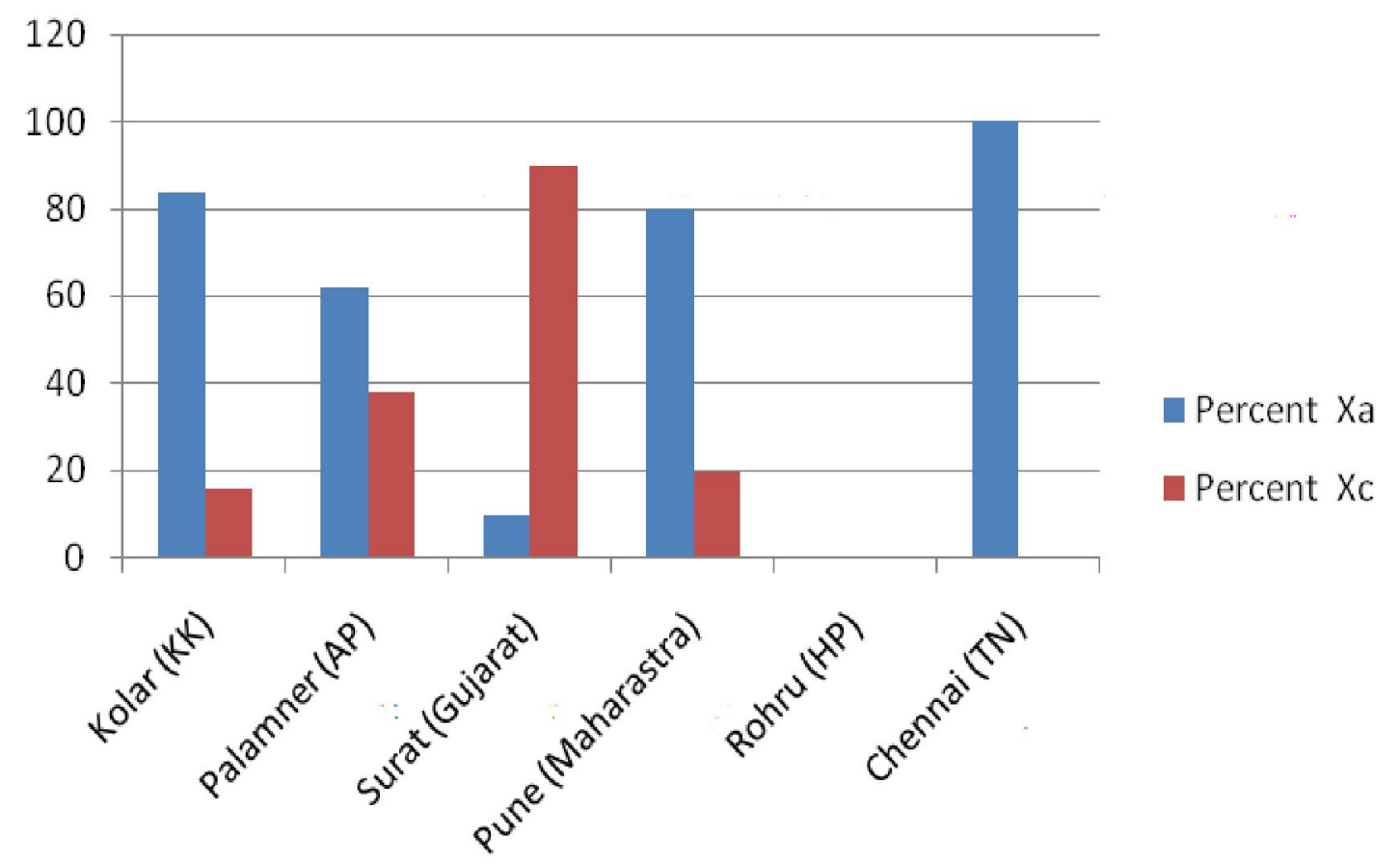

Fig. 3. Biodiversity of plague vector species in different areas.

Table 4. Data on biodiver sity of plague vector in different areas.

\begin{tabular}{|c|c|c|c|c|c|c|}
\hline \multirow[b]{2}{*}{ Places } & \multicolumn{3}{|c|}{ Types of Fleas } & \multirow{2}{*}{ Total } & \multicolumn{2}{|c|}{ Per cent (\%) } \\
\hline & $\mathrm{Xa}$ & $X_{c}$ & Neopsylla kawar & & $\mathrm{Xa}$ & $X c$ \\
\hline Kolar (KA) & 180 & 35 & 0 & 215 & 84 & 16 \\
\hline Palamner (AP) & 328 & 201 & 0 & 529 & 62 & 38 \\
\hline Surat (Gujarat) & 1 & 9 & 0 & 10 & 10 & 90 \\
\hline Pune (Maharastra) & 36 & 9 & 0 & 45 & 80 & 20 \\
\hline Rohru (HP) & 0 & 0 & 24 & 24 & 0 & 0 \\
\hline Chennai (TN) & 87 & 0 & 0 & 87 & 100 & 0 \\
\hline Total & 632 & 254 & 24 & 910 & 69 & 28 \\
\hline
\end{tabular}

even in the rest of period the maximum temperature does not go more than $20^{\circ} \mathrm{C}$.

$X$. species like $X$. cheopis and $X$. astia were considered as the efficient vector for plague. It may be concluded that the $X$. cheopis may be playing a major role in Gujarat state and X. astia in Karnataka and AP state. The fleas collected from the peri-domestic and wild situation were found almost same such as Xenopsylla spp. in most of the places except the Dodra Kawar area of HP state. The mass use of pesticide in crop cultivation does have impact on the flea population. It was observed that those areas where the pesticides were used, the rodents were found but no fleas were found on their body. This may results into resistance development in rodent fleas in the near future.

\section{Conclusion}

In most of the plague endemic area the rodent fleas were found. The species prevalent were Xenopsylla cheopis in Surat (Gujarat) and in Maharastra, Andhra, Karnataka and Tamil Nadu it was mainly X. astia. N eopsylla kawar was found in Dodra Kawar area of HP state which may or may not be the efficient vector because the evidence of plague organism was lacking. The female percent of rodent fleas may be considered as a good indicator for the fast propagation of rodent flea. Uses of Pesticides have got impact on rodent flea population, as the rodents were found but no fleas were found on their body. This may results into resistance development in rodent fleas in the near future.

\section{ACKNOW LEDGEMENTS}

The authors are highly grateful to the Director, NCDC, Head of Zoonosis Division and the Head of Plague Surveillance Unit for helping me to carry out the research work. Our sincere thanks are also due to all the staff of PSU and other field unit staffs who helped us in this connection.

\section{REFERENCES}

Balthazard, M. and Bahmanyar, M. (1958). Research on plague in India.WHO/Plague/46. 
Biswas, S., Kumar, R. and Lal, S. (2008). Present susceptibility status of rat flea Xenopsylla cheopis (Siphonaptera: Pullicidae), vector of plague against organochlorine, organophosphate and synthetic pyrethroids 1 . The Nilgiris District, Tamil Nadu, India.J . C omm. Diseases, 40(1): 41-5.

Biswas, S., Lal, S., Mittal, V., Malini, M. and Kumar, S., (2011). Detection of enzootic plague foci in Peninsular India. J. Comm. Diseases, 40(2): 46-55.

Bulter, Thomas (1989). The black death past and present 1 . plague in the 1980s. Trans. Royal Soc. Trop. Med. and Hygiene, 83: 458-460.

Iyengar, Ravi (1973). Iyengar : On Siphonaptera of Indian subregion. Oriental Insects Suppl., 36(1) no. 3: 2 - 25.

Krishnamurthy, B. S., Putatunda, J. N., Joshi, G. C., Chandrahas, R. K. and Krishnaswami (1965). Studies on the susceptibility of the oriental rat fleas, Xenopsylla spp. to some organophosphorus and carbamate insecticides. Bull. Ind. Soc. M al. Com. Dis., Vol. II: 131-138.
Kumar K., Katyal, R., Gill, K. S. and Jamil-Ur-Rahman, S. (1996). Prevalence of rat fleas in and around Delhi (India) area and their susceptibility status to insecticides. Japan J . Med. Soc. Bio., 49: 56-62.

Rathnaswamy, G. K. (1974). Siphonaptera. A handbook of M ed. Ent. and Elementary P arasitology. pp. 57-71.

Samuel, K. and Cohn, J. R., (2008). Epidemiology of the Black Death and successive waves of plague. Med. H ist. Suppl., 27: 74-100.

Seal, S. C. (1960). Epidemiological studies of plague in India. 2. The changing pattern of rodents and fleas in Calcutta. Bull. WId. HIth. Org., 29: 293-300.

Seal, S. C. (1969). Epidemiological studies of Plague in India. 1. The present position. Bull. Org. mond. Sante and Bull. WId. HIth. Org., 23: 283-292.

Sharma, R.M. (2012). Checklist of Indian Fleas (Insecta: Siphonaptera). ZSI, C entral Zone Regional Station J abalpur (M .P.). Retrieved on 14.10.2012 from www.zsi.gov.in. 